\title{
A Study on the Effect of Metabolic Heat Generation on Biological Tissue Freezing
}

\author{
Sonalika Singh and Sushil Kumar \\ Department of Applied Mathematics and Humanities, S. V. National Institute of Technology, Surat, Gujarat 395007, India \\ Correspondence should be addressed to Sonalika Singh; singhsonalika01@gmail.com
}

Received 7 August 2013; Accepted 20 September 2013

Academic Editors: A. Carotenuto, G. Tresset, and A. Zamyatnin

Copyright ( $) 2013$ S. Singh and S. Kumar. This is an open access article distributed under the Creative Commons Attribution License, which permits unrestricted use, distribution, and reproduction in any medium, provided the original work is properly cited.

The effect of metabolic heat generation on the freezing of biological tissue has been studied. Quasi-steady approximation is used to solve the Pennes bioheat equation in tissues. Temperature profile and motion of freezing interfaces are obtained for different values of metabolic heat generation. It is observed that metabolism has a significant effect on freezing of biological tissues during cryosurgery.

\section{Introduction}

The effect of volumetric energy generation on phase change problems is important in several applications including nuclear energy, geophysics, material processing, vivo freezing of biological tissues, and solar collectors. Cryosurgery is one of the examples that involves freezing of biological tissue in vivo. In tissues, heat is generated by metabolism and blood perfusion, and the heat, that is, generated during metabolic processes such as growth and energy production of the living system, is defined as metabolic heat.

Cryosurgery is one of the most important therapies for tumor treatment. In cryosurgery, extreme cold is used to destroy the tissue for therapeutic purpose. It involves local freezing of tissues for their controlled destruction or removal. In 1960, the concept of injecting liquid nitrogen through cryoprobe into the target tissue to freeze them from within was introduced. Several advantages of cryosurgery include the low invasiveness of the procedure, minimal blood flow, localizing the site of surgery, and reducing the recovery and hospitalization time for the patient. The earliest model of heat transfer in the biological tissue is discussed by Pennes [1]. Cryosurgery destroys cells and tissues by a complex mechanism containing ice-related factors [2]. Advantages of cryosurgery have initiated interest among researchers to apply it to the field of skin, breast, prostate, liver, and lung cancers [3-11].
The aim of cryosurgery is to maximize the damage to the undesired tissues within the defined domain and minimize the injury to the surrounding healthy tissues $[9,12]$. The parameters which influence the process of cryosurgery are the coolest temperature in the tissue, the duration of frozen cycle, the rate of freezing front propagation, the thawing rate, and the freezing-thawing cycles [13-21]. The factors which affect necrosis such as the lowest temperature in the tissue or the rate of freezing front propagation depend on the biophysical parameters that are present in a given cryosurgical procedure, some of which may be selected and controlled by the surgeons. These parameters include the temperature and duration of freezing-thawing process, the shape and size of cryoprobe, the heat capacity and thermal conductivity of the tissue, the rate of blood flow, and metabolism in the involved tissue [22]. Gage et al. [16] have studied the effect of varying freezing rate, duration of freezing and thawing cycles to investigate the effect of these factors on cell destruction in dog skin. They suggested that features like fast cooling, slow thawing, and repetition of the freeze/thaw cycle should be modified by maintaining the tissues in the frozen state for several minutes and slow thawing.

Blood perfusion and metabolic heat generation also have an important effect on heat transfer in tissues [23-26]. The coolest temperature in the tissues is one of the crucial points in the process of cryosurgery. Moreover, the duration 


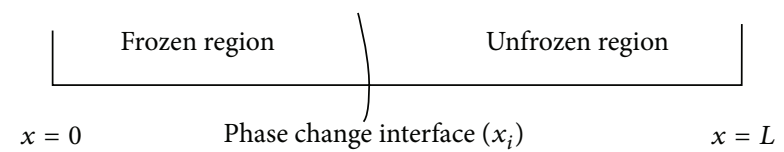

FIGURE 1: Schematic representation of one-dimensional model.

of frozen state also has much influence on the success of cryosurgery [16, 27-31]. The tissue destruction is increased when it is held in the frozen state in the temperature range at which recrystallization occurs [14]. A common problem in cryosurgery is the extent of post operative bleeding caused by parenchyma fractures and related to the thermal stress inside the target tissue [32]. Shi et al. [33] have described the large volumetric expansion having the primary contributor to large stress development during the freezing of biomaterial through ice-crystallization. The thermal gradient and the effect of volumetric expansion associated with freezing are the two most important factors that induce thermal stress [33, 34]. Consequently, the study of the thermal gradient inside the tissue is also an important issue for the optimization of cryosurgery.

The temperature transients in tumour and normal tissue are useful to say whether the tumour is damaged or not and to minimize the injury to healthy tissues during cryosurgery. There is a need for a simple analytical solution to evaluate the effect of parameters like metabolic heat generation on ice-crystallization. A process of simplification is used in solving a variety of problems which can eliminate the need for numerical solutions. In this paper, the method of quasisteady approximation to study the effect of metabolic heat generation on one-dimensional ice-crystallization during cryosurgery has been used. Temperature profiles and motion of freezing interface are obtained for different values of metabolic heat generation.

\section{Mathematical Model}

In the present study, one-dimensional ice-crystallization in biological tissue of length $L$ has been considered as shown in Figure 1. Cryoprobe with temperature $T_{0}=-196^{\circ} \mathrm{C}$ is applied at $x=0$, while at the other end $x=L$ an adiabatic condition is used. In the frozen region, blood perfusion and metabolic heat generation are zero $[4,5,10,11,13]$.

The governing equations for one-dimensional icecrystallization in biological tissue are as follows.

In frozen region:

$$
\rho_{f} c_{f} \frac{\partial T_{f}}{\partial t}=k_{f} \frac{\partial^{2} T_{f}}{\partial x^{2}} \quad \text { for } 0 \leq x \leq x_{i}
$$

In unfrozen region:

$$
\rho_{u} c_{u} \frac{\partial T_{u}}{\partial t}=k_{u} \frac{\partial^{2} T_{u}}{\partial x^{2}}+q_{b}+q_{m} \quad \text { for } x_{i} \leq x \leq L .
$$

Initial conditions:

$$
\begin{aligned}
& T_{u}(x, 0)=T_{I}=37^{\circ} \mathrm{C}, \\
& T_{f}(x, 0)=T_{I}=37^{\circ} \mathrm{C} .
\end{aligned}
$$

Boundary conditions:

$$
\begin{gathered}
T_{f}(0, t)=T_{0}=-196^{\circ} \mathrm{C}, \\
\frac{\partial T_{u}(L, t)}{\partial x}=0 .
\end{gathered}
$$

Conditions at phase change interface:

$$
\begin{gathered}
T_{f}\left(x_{i}, t\right)=T_{\mathrm{ph}}=T_{u}\left(x_{i}, t\right), \\
k_{f} \frac{\partial T_{f}\left(x_{i}, t\right)}{\partial x}-k_{u} \frac{\partial T_{u}\left(x_{i}, t\right)}{\partial x}=\rho_{u} l \frac{d x_{i}}{d t},
\end{gathered}
$$

where $\rho$ is the density of tissue; $c$ the specific heat; $k$ the thermal conductivity; $x_{i}$ the interface position of freezing front; $T$ the temperature; $x$ the space coordinate; $t$ the time; $q_{b}$ the blood perfusion term; $l$ the latent heat of fusion; and $q_{m}$ the metabolic heat generation in the tissue. Subscripts $u$ and $f$ are for unfrozen and frozen state, respectively, and ph and $I$ are for phase change and initial states, respectively. Assuming the negligible effect of blood perfusion and using the following dimensionless variables and constants:

$$
\begin{gathered}
\alpha_{f}=\frac{k_{f}}{\rho_{f} c_{f}}, \quad \alpha_{u}=\frac{k_{u}}{\rho_{u} c_{u}}, \quad \alpha^{*}=\frac{\alpha_{u}}{\alpha_{f}}, \\
x^{*}=\frac{x}{L}, \quad t^{*}=\frac{\alpha_{u} t}{L^{2}} \text { Ste, } \quad K^{*}=\frac{k_{u}}{k_{f}}, \\
T_{f}^{*}=\frac{T_{f}-T_{0}}{T_{\mathrm{ph}}-T_{0}}, \quad T_{u}^{*}=\frac{T_{u}-T_{0}}{T_{\mathrm{ph}}-T_{0}}, \\
q_{m}^{*}=\frac{q_{m} L^{2}}{k_{u}\left(T_{\mathrm{ph}}-T_{0}\right)},
\end{gathered}
$$

where Ste is the Stefan number defined as Ste $=c_{u}\left(T_{\mathrm{ph}}-T_{0}\right) / l$.

Equations (1) and (2) become

$$
\begin{gathered}
\text { Ste } \alpha^{*} \frac{\partial T_{f}^{*}}{\partial t^{*}}=\frac{\partial^{2} T_{f}^{*}}{\partial x^{* 2}} \quad \text { for } 0 \leq x^{*} \leq x_{i}^{*}, \\
\text { Ste } \frac{\partial T_{u}^{*}}{\partial t^{*}}=\frac{\partial^{2} T_{u}^{*}}{\partial x^{* 2}}+q_{m}^{*} \quad \text { for } x_{i}^{*} \leq x^{*} \leq 1 .
\end{gathered}
$$

The initial and boundary conditions (3)-(4) become

$$
\begin{gathered}
T_{f}^{*}\left(x^{*}, 0\right)=\frac{T_{I}-T_{0}}{T_{\mathrm{ph}}-T_{0}}, \\
T_{u}^{*}\left(x^{*}, 0\right)=\frac{T_{I}-T_{0}}{T_{\mathrm{ph}}-T_{0}}, \\
T_{f}^{*}\left(0, t^{*}\right)=0, \\
\frac{\partial T_{u}^{*}\left(1, t^{*}\right)}{\partial x}=0 .
\end{gathered}
$$


Condition at phase change interface equations (5) is transformed to

$$
\begin{gathered}
T_{f}^{*}\left(x_{i}^{*}, t^{*}\right)=1=T_{u}^{*}\left(x_{i}^{*}, t^{*}\right), \\
\frac{1}{K^{*}} \frac{\partial T_{f}^{*}\left(x_{i}^{*}, t^{*}\right)}{\partial x^{*}}-\frac{\partial T_{u}^{*}\left(x_{i}^{*}, t^{*}\right)}{\partial x^{*}}=\frac{d x_{i}^{*}}{d t^{*}} .
\end{gathered}
$$

\section{Quasi-Steady Approximation}

Due to nonlinearity of the interface energy equation, there are few exact solutions to the problems with phase change. The condition at phase change equation is nonlinear because the interface velocity $d x_{i} / d t$ depends on the temperature gradients. In this model, the Stefan number is taken small compared to the unity. A small Stefan number corresponds to the sensible heat which is small compared to the latent heat. The interface moves slowly for a small Stefan number, and the temperature distribution at each instant corresponds to that of steady-state. Quasi-steady approximation is justified for Ste $<0.1[35,36]$. Setting Ste $=0$ in $(7)$ and we get

$$
\begin{gathered}
\frac{\partial^{2} T_{f}^{*}}{\partial x^{* 2}}=0 \\
\frac{\partial^{2} T_{u}^{*}}{\partial x^{* 2}}+q_{m}^{*}=0 .
\end{gathered}
$$

Integrating (13) and using boundary conditions given by (9) and (11), the temperature distribution in frozen region is obtained as

$$
T_{f}^{*}\left(x^{*}, t^{*}\right)=\frac{x^{*}}{x_{i}^{*}} .
$$

Integrating (14) with boundary conditions given by (10) and (11), the temperature distribution in the unfrozen region is given as

$$
T_{u}^{*}\left(x^{*}, t^{*}\right)=\frac{q_{m}^{*}}{2}\left(x_{i}^{* 2}-x^{* 2}\right)+q_{m}^{*}\left(x^{*}-x_{i}^{*}\right)+1 .
$$

Substituting the temperature of frozen and unfrozen regions given by (15) and (16) into the condition at phase change interface given by (12), we obtain

$$
\frac{q_{m}^{*} K^{*} x_{i}^{* 2}-q_{m}^{*} K^{*} x_{i}^{*}+1}{K^{*} x_{i}^{*}}=\frac{d x_{i}^{*}}{d t^{*}} .
$$

Integrating (17) and utilizing the initial condition at $x_{i}^{*}$,

$$
\begin{gathered}
\int_{0}^{t^{*}} d t^{*}=\int_{0}^{x_{i}^{*}} \frac{K^{*} x_{i}^{*} d x_{i}^{*}}{q_{m}^{*} K^{*} x_{i}^{* 2}-q_{m}^{*} K^{*} x_{i}^{*}+1}, \\
t^{*}=\frac{1}{2 q_{m}^{*}}\left[\log \left|q_{m}^{*} K^{*} x_{i}^{* 2}-q_{m}^{*} K^{*} x_{i}^{*}+1\right|\right. \\
\left.+q_{m}^{*} K^{*} \int_{0}^{x_{i}^{*}} \frac{d x_{i}^{*}}{q_{m}^{*} K^{*} x_{i}^{* 2}-q_{m}^{*} K^{*} x_{i}^{*}+1}\right] .
\end{gathered}
$$

In (19), the value of $q_{m}^{*}$ is unknown. Due to the unknown value of $q_{m}^{*}$, there arise three possibilities. Therefore, we evaluate the above integral considering the three cases which are mentioned below.

Case $1\left(q_{m}^{*} K^{*}>4, t^{*} \geq 0\right)$. From (19) we have

$$
\begin{aligned}
& t^{*}=\frac{1}{2 q_{m}^{*}} \log \left|q_{m}^{*} K^{*} x_{i}^{* 2}-q_{m}^{*} K^{*} x_{i}^{*}+1\right| \\
& +\frac{K^{*}}{2} \int_{0}^{x_{i}^{*}} \frac{d x_{i}^{*}}{q_{m}^{*} K^{*} x_{i}^{* 2}-q_{m}^{*} K^{*} x_{i}^{*}+1} \\
& =\frac{1}{2 q_{m}^{*}} \log \left|q_{m}^{*} K^{*} x_{i}^{* 2}-q_{m}^{*} K^{*} x_{i}^{*}+1\right| \\
& +\frac{1}{2 q_{m}^{*}} \int_{0}^{x_{i}^{*}} \frac{d x_{i}^{*}}{x_{i}^{* 2}-x_{i}^{*}+\left(1 / q_{m}^{*} K^{*}\right)} \\
& =\frac{1}{2 q_{m}^{*}} \log \left|q_{m}^{*} K^{*} x_{i}^{* 2}-q_{m}^{*} K^{*} x_{i}^{*}+1\right|+\frac{1}{2 q_{m}^{*}} \\
& \times \int_{0}^{x_{i}^{*}}\left(d x _ { i } ^ { * } \left(\left\{x_{i}^{*}-\frac{1}{2}\left(1+\sqrt{1-\frac{4}{q_{m}^{*} K^{*}}}\right)\right\}\right.\right. \\
& \left.\left.\times\left\{x_{i}^{*}-\frac{1}{2}\left(1-\sqrt{1-\frac{4}{q_{m}^{*} K^{*}}}\right)\right\}\right)^{-1}\right) \\
& =\frac{1}{2 q_{m}^{*}} \log \left|q_{m}^{*} K^{*} x_{i}^{* 2}-q_{m}^{*} K^{*} x_{i}^{*}+1\right| \\
& +\frac{K^{*}}{\sqrt{q_{m}^{* 2} K^{* 2}-4 q_{m}^{*} K^{*}}} \\
& \times \log \left|\frac{2 q_{m}^{*} K^{*} x_{i}^{*}-q_{m}^{*} K^{*}-\sqrt{q_{m}^{* 2} K^{* 2}-4 q_{m}^{*} K^{*}}}{2 q_{m}^{*} K^{*} x_{i}^{*}-q_{m}^{*} K^{*}+\sqrt{q_{m}^{* 2} K^{* 2}-4 q_{m}^{*} K^{*}}}\right| \\
& -\frac{K^{*}}{\sqrt{q_{m}^{* 2} K^{* 2}-4 q_{m}^{*} K^{*}}} \\
& \times \log \left|\frac{-q_{m}^{*} K^{*}-\sqrt{q_{m}^{* 2} K^{* 2}-4 q_{m}^{*} K^{*}}}{-q_{m}^{*} K^{*}+\sqrt{q_{m}^{* 2} K^{* 2}-4 q_{m}^{*} K^{*}}}\right| .
\end{aligned}
$$

Case $2\left(q_{m}^{*} K^{*}<4, T^{*} \geq 0\right)$. From (19) we have

$$
\begin{aligned}
t^{*}= & \frac{1}{2 q_{m}^{*}} \log \left|q_{m}^{*} K^{*} x_{i}^{* 2}-q_{m}^{*} K^{*} x_{i}^{*}+1\right| \\
& +\frac{K^{*}}{2} \int_{0}^{x_{i}^{*}} \frac{d x_{i}^{*}}{q_{m}^{*} K^{*} x_{i}^{* 2}-q_{m}^{*} K^{*} x_{i}^{*}+1} \\
= & \frac{1}{2 q_{m}^{*}} \log \left|q_{m}^{*} K^{*} x_{i}^{* 2}-q_{m}^{*} K^{*} x_{i}^{*}+1\right| \\
& +\frac{1}{2 q_{m}^{*}} \int_{0}^{x_{i}^{*}} \frac{d x_{i}^{*}}{x_{i}^{* 2}-x_{i}^{*}+\left(1 / q_{m}^{*} K^{*}\right)}
\end{aligned}
$$


TABLE 1: Thermal properties of tissues [13, 23].

\begin{tabular}{lc}
\hline Parameter & Value \\
\hline Density of unfrozen tissue $\left(\mathrm{kg} / \mathrm{m}^{3}\right)$ & 1050 \\
Density of frozen tissue $\left(\mathrm{kg} / \mathrm{m}^{3}\right)$ & 921 \\
Specific heat of unfrozen tissue $\left(\mathrm{J} / \mathrm{kg}{ }^{\circ} \mathrm{C}\right)$ & 3770 \\
Specific heat of frozen tissue $\left(\mathrm{J} / \mathrm{kg}{ }^{\circ} \mathrm{C}\right)$ & 1800 \\
Thermal conductivity of unfrozen tissue $\left(\mathrm{W} / \mathrm{m}{ }^{\circ} \mathrm{C}\right)$ & 0.5 \\
Thermal conductivity of frozen tissue $\left(\mathrm{W} / \mathrm{m}^{\circ} \mathrm{C}\right)$ & 2 \\
Latent heat $(\mathrm{KJ} / \mathrm{kg})$ & 250 \\
The phase change temperature $\left({ }^{\circ} \mathrm{C}\right)$ & -8 \\
Arterial blood temperature $\left({ }^{\circ} \mathrm{C}\right)$ & 37 \\
Length of tissue $(\mathrm{m})$ & 0.04 \\
\hline
\end{tabular}

$$
\begin{aligned}
= & \frac{1}{2 q_{m}^{*}} \log \left|q_{m}^{*} K^{*} x_{i}^{* 2}-q_{m}^{*} K^{*} x_{i}^{*}+1\right| \\
& +\frac{1}{2 q_{m}^{*}} \int_{0}^{x_{i}^{*}} \frac{d x_{i}^{*}}{\left(x_{i}^{*}-(1 / 2)\right)^{2}+\left(\sqrt{\left.\left(1 / q_{m}^{*} K^{*}\right)-(1 / 4)\right)^{2}}\right.} \\
= & \frac{1}{2 q_{m}^{*}} \log \left|q_{m}^{*} K^{*} x_{i}^{* 2}-q_{m}^{*} K^{*} x_{i}^{*}+1\right| \\
& +\frac{K^{*}}{\sqrt{4 q_{m}^{*} K^{*}-q_{m}^{* 2} K^{* 2}}} \\
& \times \tan ^{-1}\left(\frac{2 q_{m}^{*} K^{*} x_{i}^{*}-q_{m}^{*} K^{*}}{\sqrt{4 q_{m}^{*} K^{*}-q_{m}^{* 2} K^{* 2}}}\right) \\
& -\frac{K^{*}}{\sqrt{4 q_{m}^{*} K^{*}-q_{m}^{* 2} K^{* 2}}} \\
& \times \tan ^{-1}\left(\frac{-q_{m}^{*} K^{*}}{\sqrt{4 q_{m}^{*} K^{*}-q_{m}^{* 2} K^{* 2}}}\right) . \\
& \\
&
\end{aligned}
$$

Case $3\left(q_{m}^{*} K^{*}=4, t^{*} \geq 0\right)$. From (19) we have

$$
\begin{aligned}
t^{*}= & \frac{1}{2 q_{m}^{*}} \log \left|q_{m}^{*} K^{*} x_{i}^{* 2}-q_{m}^{*} K^{*} x_{i}^{*}+1\right| \\
& +\frac{K^{*}}{2} \int_{0}^{x_{i}^{*}} \frac{d x_{i}^{*}}{q_{m}^{*} K^{*} x_{i}^{* 2}-q_{m}^{*} K^{*} x_{i}^{*}+1} \\
= & \frac{1}{2 q_{m}^{*}} \log \left|q_{m}^{*} K^{*} x_{i}^{* 2}-q_{m}^{*} K^{*} x_{i}^{*}+1\right| \\
& +\frac{1}{2 q_{m}^{*}} \int_{0}^{x_{i}^{*}} \frac{d x_{i}^{*}}{x_{i}^{* 2}-x_{i}^{*}+\left(1 / q_{m}^{*} K^{*}\right)} \\
= & \frac{1}{2 q_{m}^{*}} \log \left|q_{m}^{*} K^{*} x_{i}^{* 2}-q_{m}^{*} K^{*} x_{i}^{*}+1\right| \\
& -\frac{1}{2 q_{m}^{*} x_{i}^{*}-q_{m}^{*}}-\frac{1}{q_{m}^{*}} .
\end{aligned}
$$

TABLE 2: Penetration distance of interface and time taken for different values of $q_{m}^{*}$.

\begin{tabular}{lccc}
\hline$q_{m}^{*}$ & $q_{m}\left(\mathrm{~W} / \mathrm{m}^{3}\right)$ & $\begin{array}{c}\text { Interface penetration } \\
\text { distance } x_{i}^{*}\end{array}$ & Time $t^{*}$ \\
\hline 13 & 763750 & 1 & 0.3596 \\
13.5 & 793125 & 1 & 0.4009 \\
14 & 822500 & 1 & 0.4571 \\
14.5 & 851875 & 1 & 0.5402 \\
15 & 881250 & 1 & 0.6807 \\
15.5 & 910625 & 1 & 1.0008 \\
16 & 940000 & 0.4 & 0.1494 \\
16.5 & 989375 & 0.4 & 0.6673 \\
17 & 998750 & 0.3 & 0.1554 \\
17.5 & 1028125 & 0.3 & 0.1747 \\
18 & 1057500 & 0.3 & 0.2036 \\
18.5 & 1086875 & 0.3 & 0.2561 \\
\hline
\end{tabular}

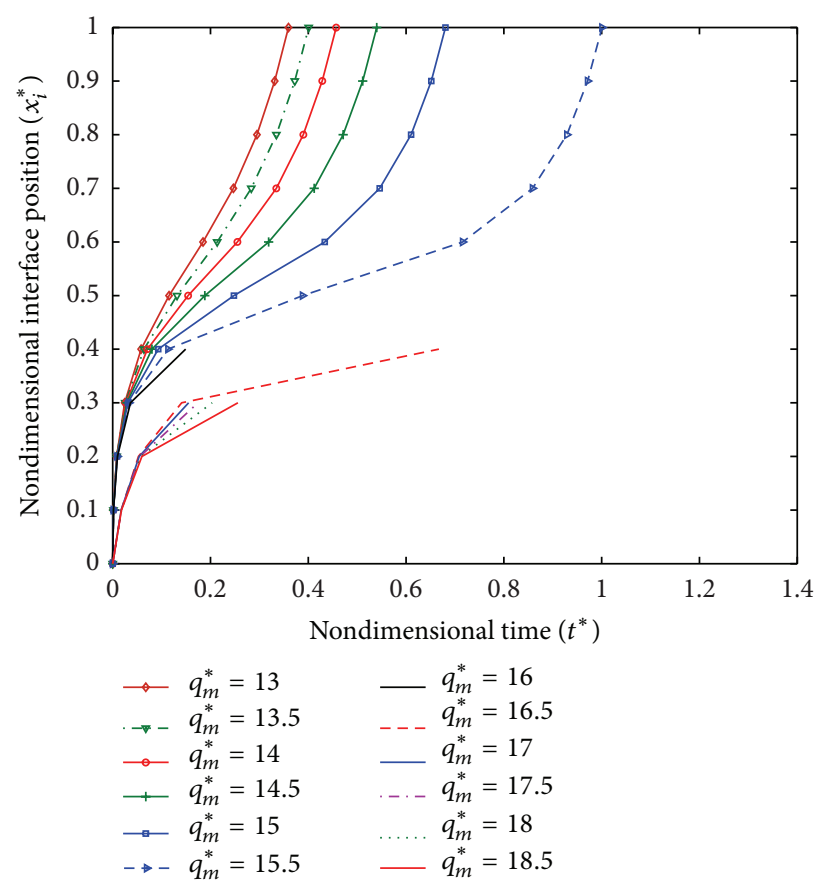

FIGURE 2: Interface position with time.

\section{Results and Discussion}

The values of parameters used are given in Table $1[13,23]$. The position of freezing interface with time for different values of $q_{m}^{*}$ is plotted in Figure 2. It is observed that when $q_{m}^{*}<16$ (i.e., $q_{m}<940000 \mathrm{~W} / \mathrm{m}^{3}$ ), the freezing interface reaches to the boundary $x=L$ and the time require for solidification of the complete tissue increases with the increase in $q_{m}$. When $q_{m}^{*} \geq 16$ (i.e., $q_{m} \geq 940000 \mathrm{~W} / \mathrm{m}^{3}$ ), the interface does not reach to the boundary $x=L$; this is because the equilibrium between cooling and heat generation is obtained before the fully freezing of tissue, and, hence, freezing interface does not move forward. Total penetration distance of freezing 


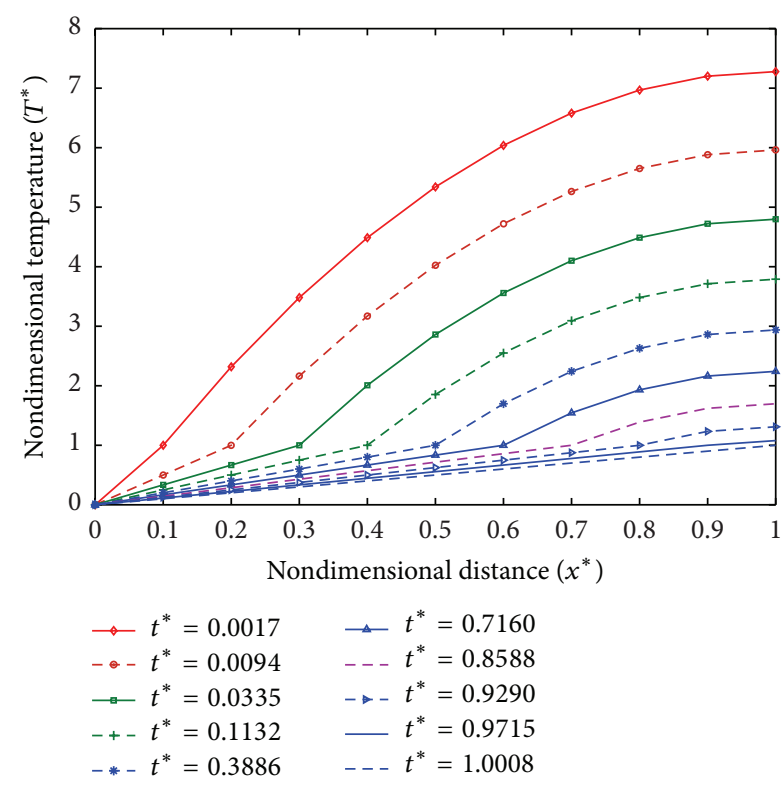

FIgURE 3: Temperature distribution at $q_{m}^{*}=15.5$.

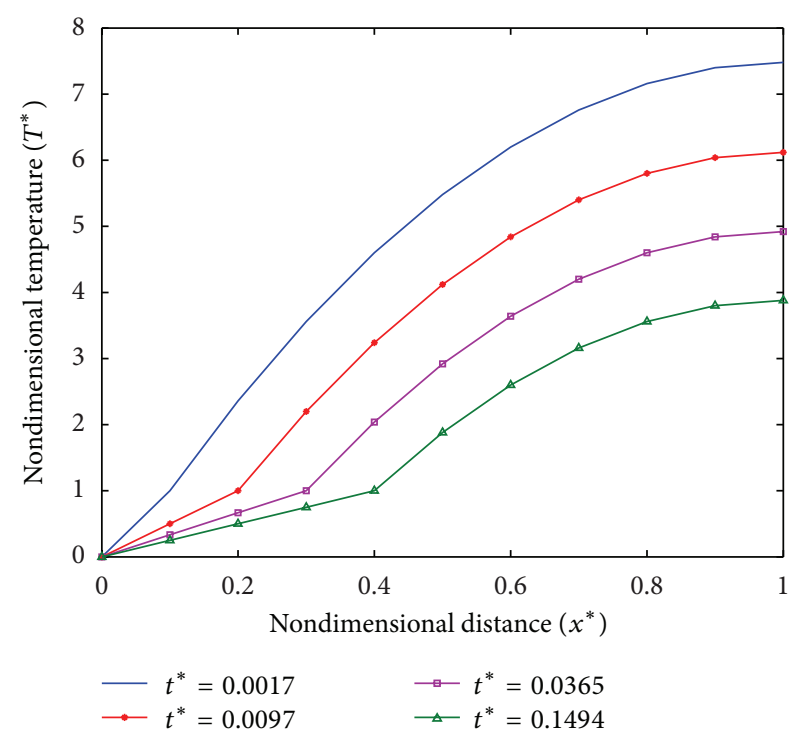

FIgURE 4: Temperature distribution at $q_{m}^{*}=16$.

interface and time taken as given in Table 2 show that freezing slows down with the increase in metabolic heat generation.

The temperature profiles are required to optimize the damage to diseased tissues. Temperature profiles for different values of $q_{m}^{*}$, that is, $q_{m}^{*}=15.5, q_{m}^{*}=16$, and $q_{m}^{*}=16.5$, are plotted in Figures 3, 4, and 5, respectively. From Figure 3, it is observed that temperature in tissue decreases with the increase in time, and at $t^{*}=1.0008$ it is in frozen state. While in case of $q_{m}^{*}=16$ as shown in Figure 4 , a steady state is obtained at $t^{*}=0.1494$ and tissue is partially frozen. Similarly, for $q_{m}^{*} \geq 16$, the partially frozen state of tissue is observed in steady state at $t^{*}=0.6673$ (Figure 5).

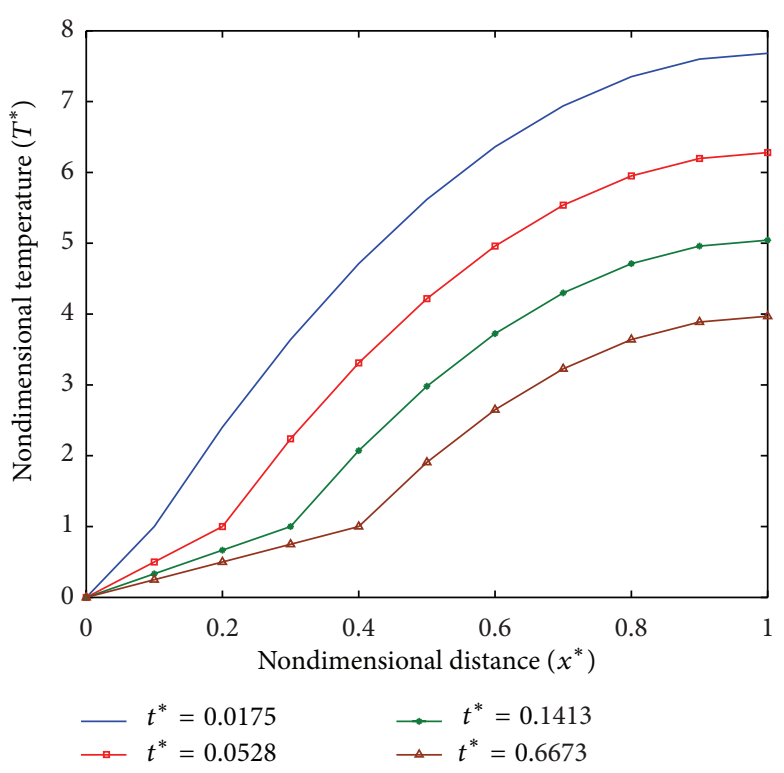

FIgURE 5: Temperature distribution at $q_{m}^{*}=16.5$.

\section{Conclusion}

A quasi-steady approximation is used to get the temperature profile and position of freezing interface in the biological tissue during the freezing of biological tissues for different values of metabolic heat generation. It is observed that the freezing process slows down with increase in metabolic heat generation. Freezing of the entire tissue is even not possible when the value of metabolic heat generation is extended to a higher value. This shows that metabolism has a significant effect on the freezing of biological tissues during cryosurgery. The obtained information can be used to optimize the treatment planning.

\section{Nomenclature}

$x:$ Distance $(0 \leq x \leq L)(\mathrm{m})$

$L: \quad$ Length of tissue $(\mathrm{m})$

$x_{i}$ : Position of freezing interface $(\mathrm{m})$

$t$ : Time (s)

T: Temperature $\left({ }^{\circ} \mathrm{C}\right)$

$\rho:$ Density $\left(\mathrm{kg} / \mathrm{m}^{3}\right)$

$c$ : Specific heat $\left(\mathrm{J} / \mathrm{kg}{ }^{\circ} \mathrm{C}\right)$

$\alpha$ : Thermal diffusivity $\left(\mathrm{m}^{2} / \mathrm{sec}\right)$

$k$ : Thermal conductivity $\left(\mathrm{W} / \mathrm{m}^{\circ} \mathrm{C}\right)$

l: $\quad$ Latent heat $(\mathrm{KJ} / \mathrm{kg})$

$q_{m}:$ Metabolic heat generation $\left(\mathrm{W} / \mathrm{m}^{3}\right)$

$q_{b}$ : Blood perfusion term $\left(\mathrm{W} / \mathrm{m}^{3}{ }^{\circ} \mathrm{C}\right)$.

\section{Subscripts}

ph: Phase change

$f$ : Frozen state

$u$ : Unfrozen state

I: $\quad$ Initial state $(t=0)$

o: Cryoprobe. 


\section{Superscript}

*: Dimensionless.

\section{Conflict of Interests}

The authors declare that there is no conflict of interests regarding the publication of this paper.

\section{Acknowledgment}

Sonalika Singh is thankful to S. V. National Institute of Technology, Surat, India, for providing Senior Research Fellowship during the preparation of this paper.

\section{References}

[1] H. H. Pennes, "Analysis of tissue and arterial blood temperatures in the resting human forearm," Journal of Applied Physiology, vol. 1, pp. 93-122, 1948.

[2] J. G. Baust, A. A. Gage, D. Clarke, J. M. Baust, and R. Van Buskirk, "Cryosurgery-a putative approach to molecularbased optimization," Cryobiology, vol. 48, no. 2, pp. 190-204, 2004.

[3] E. G. Kuflik and A. A. Gage, "The five-year cure rate achieved by cryosurgery for skin cancer," Journal of the American Academy of Dermatology, vol. 24, no. 6, pp. 1002-1004, 1991.

[4] A. A. Gage, J. A. Caruana Jr., and M. Montes, "Critical temperature for skin necrosis in experimental cryosurgery," Cryobiology, vol. 19, no. 3, pp. 273-282, 1982.

[5] S. Kumar and V. K. Katiyar, "Mathematical modeling of thawing problem in skin and subcutaneous tissue," in Proceedings of the IFMBE 6th World Congress of Biomechanics (WCB '10), C. T. Lim and J. C. H. Goh, Eds., pp. 1611-1614, August 2010.

[6] E. D. Staren, M. S. Sabel, L. M. Gianakakis et al., "Cryosurgery of breast cancer," Archives of Surgery, vol. 132, no. 1, pp. 28-34, 1997.

[7] D. K. Bahn, F. Lee, R. Badalament, A. Kumar, J. Greski, and M. Chernick, "Targeted cryoablation of the prostate: 7-year outcomes in the primary treatment of prostate cancer," Urology, vol. 60 , no. 2, pp. 3-11, 2002.

[8] R. Adam, E. Akpinar, M. Johann, F. Kunstlinger, P. Majno, and H. Bismuth, "Place of cryosurgery in the treatment of malignant liver tumors," Annals of Surgery, vol. 225, no. 1, pp. 39-50, 1997.

[9] J. C. Bischof, J. Bastacky, and B. Rubinsky, "An analytical study of cryosurgery in the lung," ASME Journal of Biomechanical Engineering, vol. 114, no. 4, pp. 467-472, 1992.

[10] S. Kumar and V. K. Katiyar, "Numerical study on phase change heat transfer during combined hyperthermia and cryosurgical treatment of lung cancer," Journal of Applied Mathematics and Mechanics, vol. 3, no. 3, pp. 1-17, 2007.

[11] S. Kumar, S. Ali, and V. K. Katiyar, "A parametric study on phase change heat transfer process during cryosurgery of lung tumor," Indian Journal of Biomechanics, no. 7-8, pp. 210-213, 2009.

[12] K. J. Chua, S. K. Chou, and J. C. Ho, "An analytical study on the thermal effects of cryosurgery on selective cell destruction," Journal of Biomechanics, vol. 40, no. 1, pp. 100-116, 2007.

[13] S. Kumar and V. K. Katiyar, "Mathematical modeling of freezing and thawing process in tissues: a porous media approach," International Journal of Applied Mechanics, vol. 2, no. 3, pp. 617633, 2010.
[14] A. A. Gage and J. Baust, "Mechanisms of tissue injury in cryosurgery," Cryobiology, vol. 37, no. 3, pp. 171-186, 1998.

[15] J. J. Smith and J. Fraser, "An estimation of tissue damage and thermal history in the cryolesion," Cryobiology, vol. 11, no. 2, pp. 139-147, 1974.

[16] A. A. Gage, K. Guest, M. Montes, J. A. Caruana, and D. A. Whalen Jr., "Effect of varying freezing and thawing rates in experimental cryosurgery," Cryobiology, vol. 22, no. 2, pp. 175$182,1985$.

[17] T. C. Hua and H. S. Ren, Cryobiomedical Techniques, Science Press, Beijing, China, 1994.

[18] R. H. Miller and P. Mazur, "Survival of frozen thawed human red cells as a function of cooling and warming velocities," Cryobiology, vol. 13, no. 4, pp. 404-414, 1976.

[19] A. A. Gage, J. A. Caruana Jr., and M. Montes, "Critical temperature for skin necrosis in experimental cryosurgery," Cryobiology, vol. 19, no. 3, pp. 273-282, 1982.

[20] J. N. Tackenberg, "Cryolumpectomy: another option for breast cancer," Nursing, vol. 20, no. 5, pp. 32J-40J, 1990.

[21] R. W. Rand, R. P. Rand, and F. A. Eggerding, "Cryolumpectomy for breast cancer: an experimental study," Cryobiology, vol. 22, no. 4, pp. 307-318, 1985.

[22] R. I. Andrushkiw, "Mathematical modeling of freezing front propagation in biological tissue," Mathematical and Computer Modelling, vol. 13, no. 10, pp. 1-9, 1990.

[23] Y. Rabin and A. Shitzer, "Numerical solution of multidimensional freezing problem during cryosurgery," Journal of Biomechanical Engineering, vol. 120, no. 1, pp. 32-37, 1998.

[24] J. C. Rewcastle, G. A. Sandison, K. Muldrew, J. C. Saliken, and B. J. Donnelly, "A model for the time dependent threedimensional thermal distribution within iceballs surrounding multiple cryoprobes," Medical Physics, vol. 28, no. 6, pp. 11251137, 2001.

[25] Z.-S. Deng and J. Liu, "Numerical simulation of 3-D freezing and heating problems for combined cryosurgery and hyperthermia therapy," Numerical Heat Transfer A, vol. 46, no. 6, pp. 587$611,2004$.

[26] G. Zhao, H.-F. Zhang, X.-J. Guo, D.-W. Luo, and D.-Y. Gao, "Effect of blood flow and metabolism on multidimensional heat transfer during cryosurgery," Medical Engineering and Physics, vol. 29, no. 2, pp. 205-215, 2007.

[27] E. D. Staren, M. S. Sabel, L. M. Gianakakis et al., "Cryosurgery of breast cancer," Archives of Surgery, vol. 132, no. 1, pp. 28-34, 1997.

[28] J. C. Bischof, D. Smith, P. V. Pazhayannur, C. Manivel, J. Hulbert, and K. P. Roberts, "Cryosurgery of dunning AT-1 rat prostate tumor: thermal, biophysical, and viability response at the cellular and tissue level," Cryobiology, vol. 34, no. 1, pp. 4269, 1997.

[29] S. M. Burge, J. P. Shepherd, and R. P. R. Dawber, "Effect of freezing the helix and the rim or edge of the human and pig ear," Journal of Dermatologic Surgery and Oncology, vol. 10, no. 10, pp. 816-819, 1984.

[30] A. A. Gage, "Experimental cryogenic injury of the palate: observations pertinent to cryosurgical destruction of tumors," Cryobiology, vol. 15, no. 4, pp. 415-425, 1978.

[31] G. Jacob, M. N. Kurzer, and B. J. Fuller, "An assessment of tumor cell viability after in vitro freezing," Cryobiology, vol. 22, no. 5 , pp. 417-426, 1985.

[32] X. M. He and J. C. Bischof, "Analysis of thermal stress in cryosurgery of kidneys," Journal of Biomechanical Engineering, vol. 127, no. 4, pp. 656-661, 2005. 
[33] X. Shi, A. K. Datta, and Y. Mukherjee, "Thermal stresses from large volumetric expansion during freezing of biomaterials," ASME Journal of Biomechanical Engineering, vol. 120, no. 6, pp. 720-726, 1998.

[34] B. Rubinsky, E. G. Cravalho, and B. Mikic, “Thermal stresses in frozen organs," Cryobiology, vol. 17, no. 1, pp. 66-73, 1980.

[35] L. M. Jiji, Heat Conduction, Springer, Berlin, Germany, 3rd edition, 2009.

[36] J. Crank, The Mathematics of Diffusion, Oxford Science Publications, 2nd edition, 1975. 

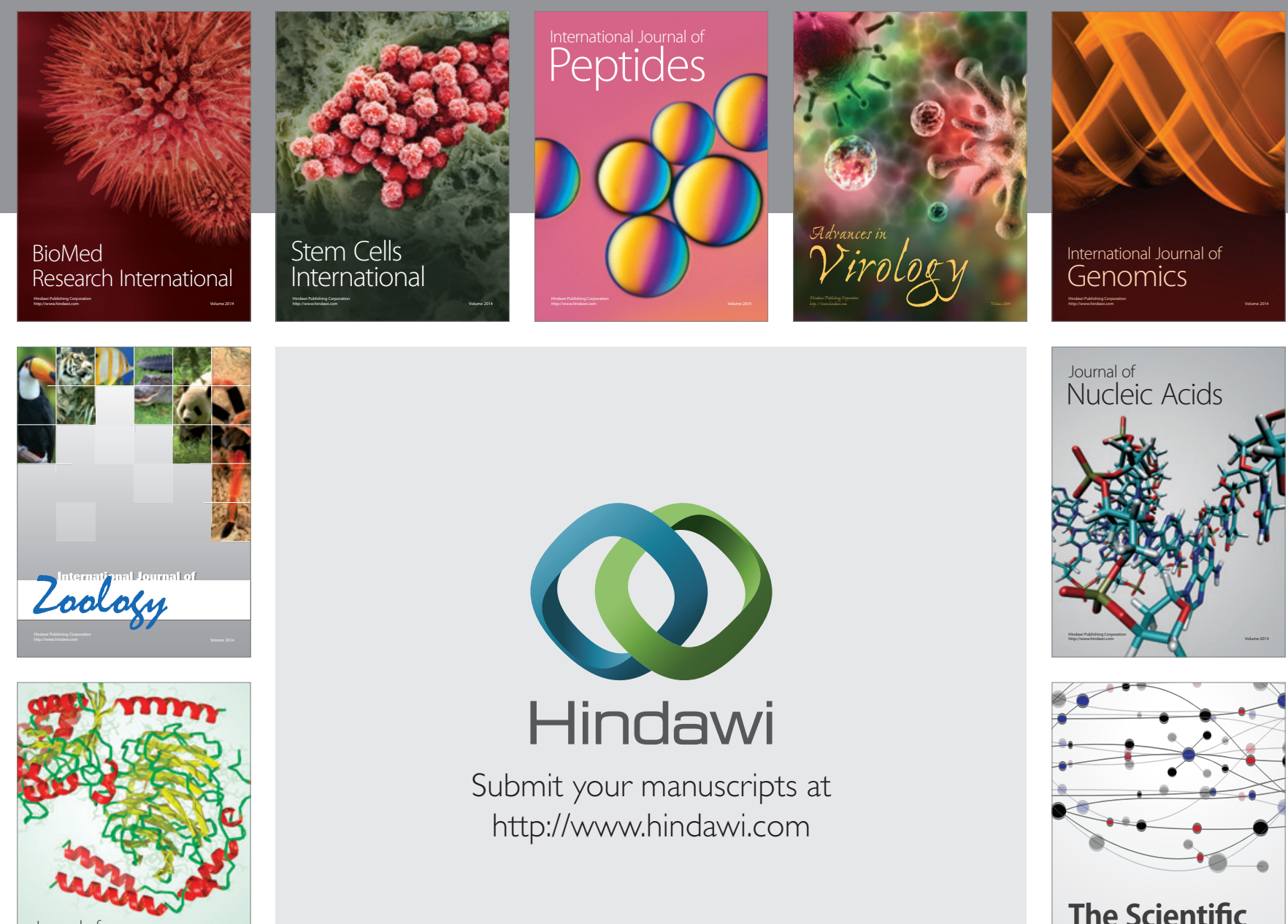

Submit your manuscripts at

http://www.hindawi.com

Journal of
Signal Transduction
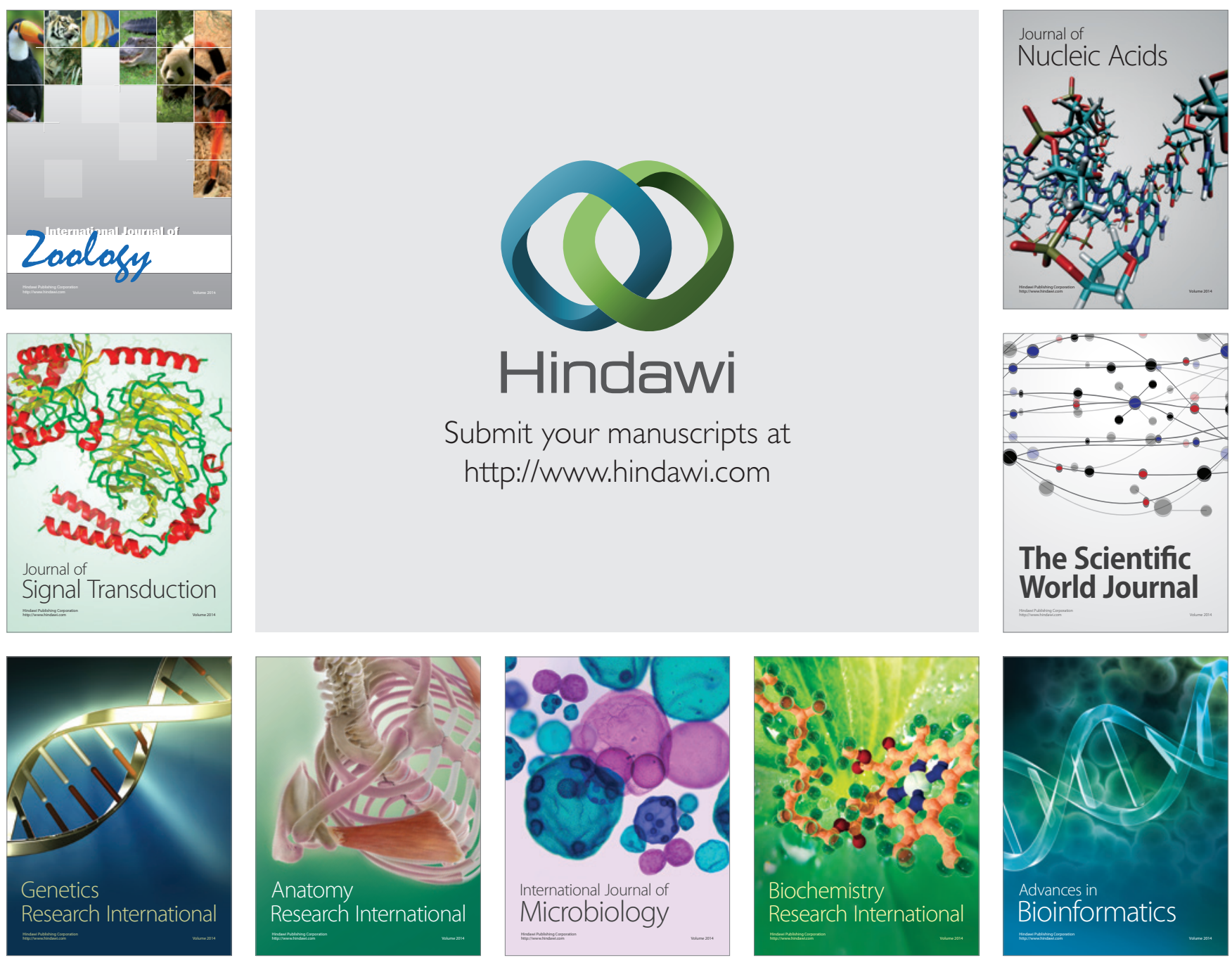

The Scientific World Journal
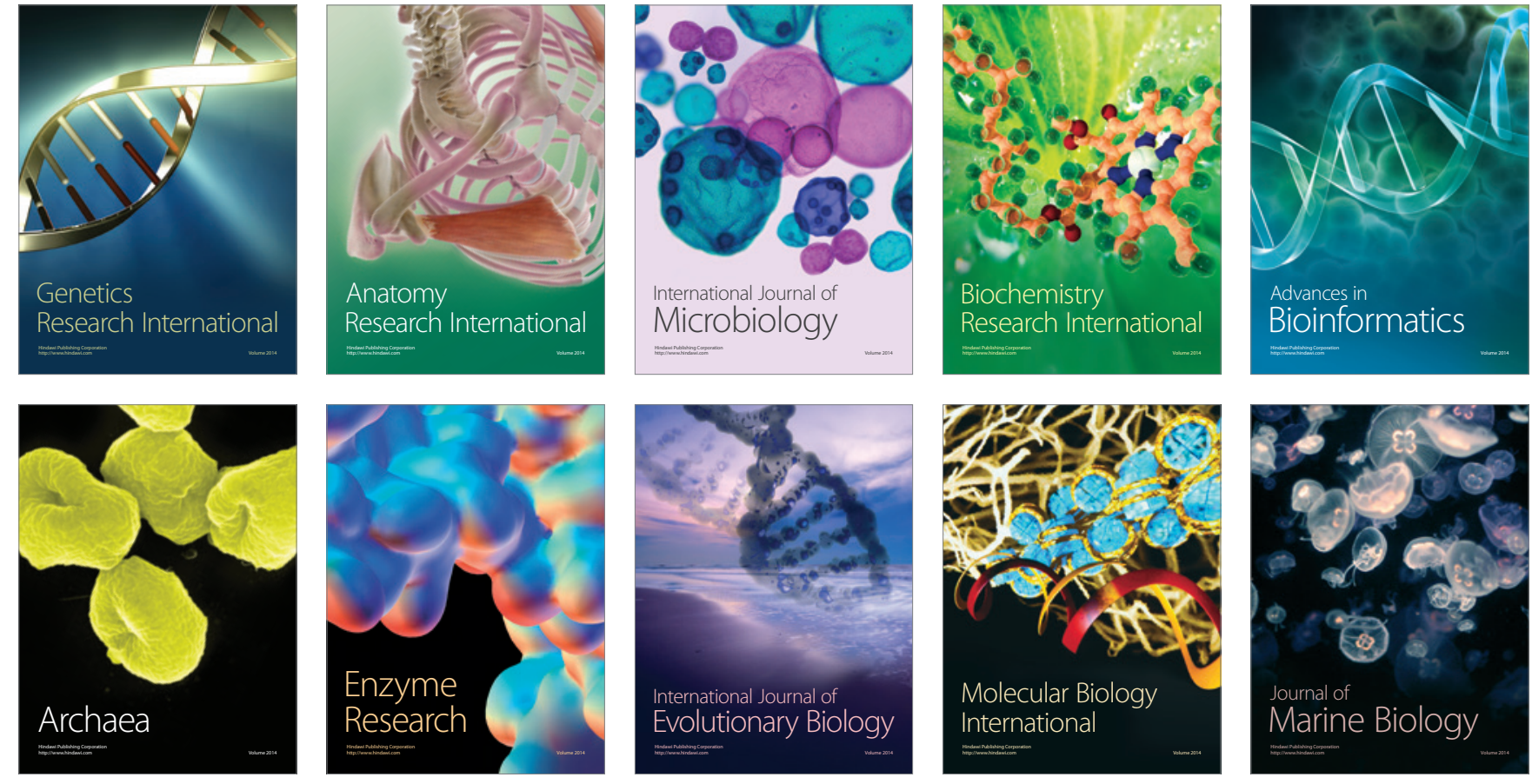